\section{UK asbestos}

\section{Down and going out}

A NUMBER of measures aimed at reducing exposure to asbestos fibres in the workplace were announced by the British Health and Safety Commission last week. Allowable airborne concentrations for two types of asbestos will be reduced from next August and new licensing regulations have been proposed to control work on asbestos insulation or coating.

In a statement issued after the meeting the commission said "it is clear from medical reports now available that there is no longer any medical doubt about the need for controls to be as tight as possible in workplaces where asbestos is present".

The new fibre concentrations are close to the limits for accurate measurement using widely available equipment and will hasten the decline in the use of asbestos in manufacturing industry. The new limit for chrysotile (white asbestos), the least dangerous of the common forms and the only type widely used in British manufacturing, is 0.5 fibres per millilitre of air, half the previous limit. Some products, such as asbestos cement, can easily be manufactured without exceeding this limit. But for woven products, such as fireproof clothing, control can be impossible, and companies are then obliged by law to ensure that protective respiratory equipment is provided and worn.

The real pinch of the decisions reached last week will be in the area of demolition and maintenance work, which is where the highest levels have been recorded and also where engineering control methods are most difficult.

Amosite (brown asbestos) will in future be classed with crocodilite (blue asbestos) and be banned from importation or use in industry. Both, however, are still present in the insulation of many buildings and can be released in dangerous levels when the buildings are stripped or demolished. The commission has proposed new licensing regulations to eliminate that; the proposals are to be considered by government.

The commission welcomed two European Community directives agreed in June which require a formal notification and medical surveillance system.

Existing asbestos regulations apply only to the workplace, and the commission has been under strong public pressure to introduce comparable controls for the general environment. To explore that possibility, it is to initiate discussions with other government departments.

It has also to set up an asbestos industry working group which will prepare guidance on methods of engineering control and the use of protective equipment. Two of the reports the commission had before it last week were severely critical of the way existing guidance is implemented in factories, where guidelines are widely disregarded partly because of the discomfort caused by wearing protective face masks for long periods.

As the use of asbestos substitutes becomes more widespread, the commission will have to consider expert opinion that it is the physical size and shape of asbestos fibres, rather than their intrinsic chemical nature, which is responsible for their carcinogenic properties and which gives rise to asbestosis. Although most substitute fibres are much larger than asbestos fibres, and therefore less dangerous, some ceramic fibres used in insulation work might also be carcinogenic.

Tim Beardsley

\title{
Satellite weapons
}

\section{Soviets propose space ban}

THE Soviet proposals for a treaty banning the "use of force in space and from space with regard to Earth", tabled for consideration at the next session of the United Nations General Assembly, comes at a somewhat inopportune moment for the United States, which is about to test a new antisatellite missile. The timing is not necessarily deliberate. August is the appropriate time for putting down motions, and it is now two years since the previous Soviet proposals were tabled.

The existing treaties banning the militarization of space (1967 and 1979) refer only to "weapons of mass destruction". The 1981 draft would have outlawed all kinds of weapons in space but made no specific reference to antisatellite devices, upon which the new draft specifically concentrates.

The Soviet Union, ironically, has itself carried out a number of hunter-killer satellite tests during the past sixteen years, the launches being carried out under the multi-purpose Cosmos programme. The original fast fly-by interceptions were replaced in 1980-81 by the more sophisticated co-orbital flight-plan. Although the treaty, as drafted, would make it incumbent on the Soviet Union to "eliminate" any existing antisatellite devices, signing it would still leave the Soviet Union with a considerable file of test results in its military archives.

Apart from the vexed issue of verification, which the Soviets propose should be carried out using only "national technical facilities", the new draft contains several controversial points.

Clause five, for example, forbids the use of any manned spacecraft for military purposes. Since a major task of orbital manned missions is resource reconnaissance photography, what happens if a team observing, say, global crop disease patterns happens to record evidence of military preparations? Clause two forbids the use of space objects "as a means of hitting targets on Earth, in the atmosphere or in space", which could hinder geodesic research based on the accurate observation of satellite orbits since such data are also essential for the programming of intercontinental ballistic missiles. The proposed treaty would apparently also forbid signatory states from owning any means of destroying their own satellites in orbit despite international concern over the unscheduled re-entry of radioactive power packs from rogue or rerouted satellites, to say nothing of the danger of debris re-entering over a populated area.

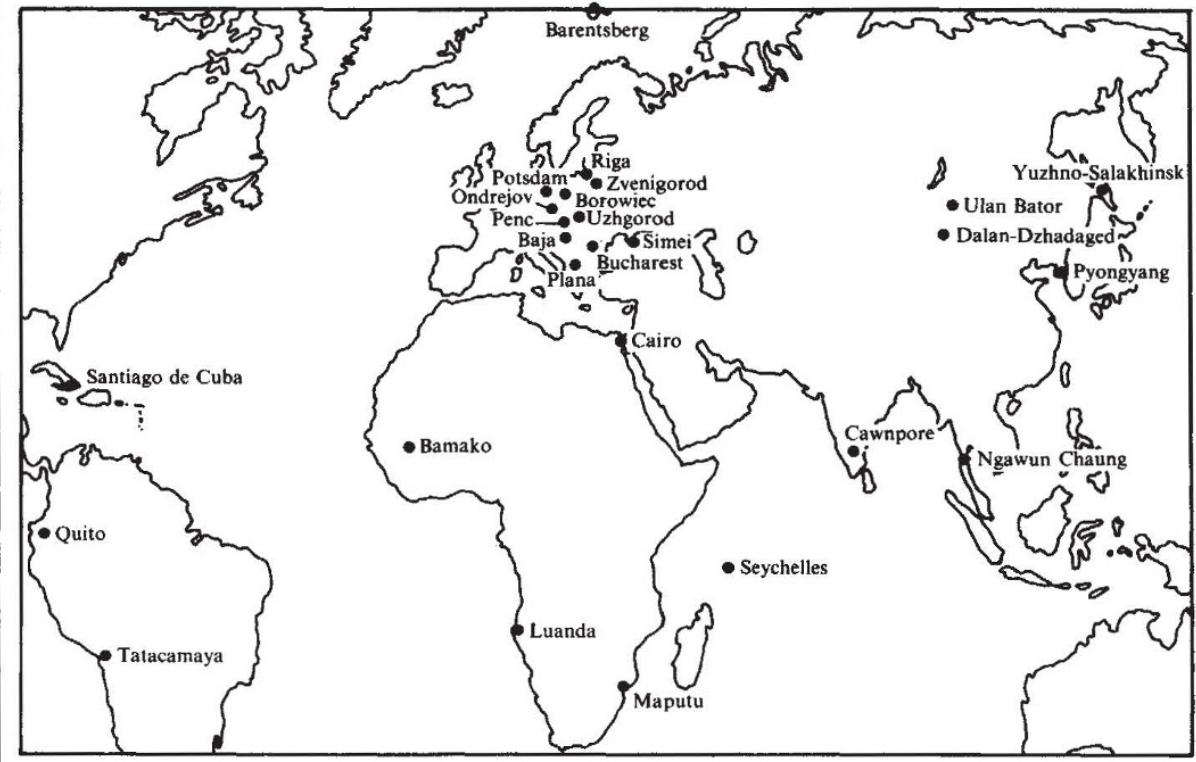

Ground stations for monitoring orbital satellites, established under the Intercosmos programme. (From Vestnik AN SSSR no. 5, 1983) 